\title{
Persistent vegetative state: an overview
}

\author{
Gabriel Alexander Quiñones-Ossa ${ }^{1 *}$ (D, Yeider A. Durango-Espinosa ${ }^{2,3}$, Tariq Janjua ${ }^{4}$, \\ Luis Rafael Moscote-Salazar ${ }^{5,6}$ and Amit Agrawal ${ }^{7}$
}

\begin{abstract}
Background: Disorder of consciousness diagnosis, especially when is classified as persistent vegetative state (without misestimating the other diagnosis classifications), in the intensive care is an important diagnosis to evaluate and treat. Persistent vegetative state diagnosis is a challenge in the daily clinical practice because the diagnosis is made mainly based upon the clinical history and the patient behavior observation. There are some specific criteria for this diagnosis, and this could be very tricky when the physician is not well trained.

Main body: We made a literature review regarding the persistent vegetative state diagnosis, clinical features, management, prognosis, and daily medical practice challenges while considering the bioethical issues and the family perspective about the patient status. The objective of this overview is to provide updated information regarding this clinical state's features while considering the current medical literature available.

Conclusions: Regardless of the currently available guidelines and literature, there is still a lot of what we do not know about the persistent vegetative state. There is a lack of evidence regarding the optimal diagnosis and even more, about how to expect a natural history of this disorder of consciousness. It is important to recall that the patients (despite of their altered mental state diagnosis) should always be treated to avoid some of the intensive care unit long-stance complications.
\end{abstract}

Keywords: Persistent vegetative state, Vegetative state, Post-traumatic vegetative state, Unresponsive wakefulness syndrome, Traumatic brain injury, Consciousness disorders, Brain damage

\section{Background}

Among all the diagnosis of prolonged states of impaired consciousness (or prolonged disorder of consciousness$\mathrm{PDoC}$ ), the persistent vegetative status (PVS) (without misestimating the others) requires special consideration due to its causes, consequences, the devastating structural brain injury, and the cost of life-time care per patient $[1,2]$. The PVS is commonly associated in patients who suffered a severe traumatic brain injury (sTBI) (without forgetting that it is also present in non-TBI episodes), as a matter of fact, TBI is one of the most important public health problems in the globe due to its incidence, mortality, and disability [3-5]. Patients who survive a sTBI might not regain consciousness; meanwhile, they can show different signs including opened

\footnotetext{
* Correspondence: gabriel.quinones.ossa@gmail.com

${ }^{1}$ Faculty of Medicine, Universidad El Bosque, Bogotá, Colombia

Full list of author information is available at the end of the article
}

eyes, fail to track objects, and circadian rhythm disturbances, all of these can be signs of an emerging PVS [6]. The prevalence varies according to the location and time. There is no consensus of the relationship of the age and sex of the patients with PVS, and its epidemiology is still unclear for many countries [1, 7-9]. This may be related to the misdiagnosis rate in these patients which is not rare [10-12], and for this reason, it might compromise clinical statistics, medical practice, and therapy approach. These subsequently lead to a barrier in the identification and the need of specialized health care for these patients [7]. The purpose of the current overview is to provide an up-to-date information of the PVS, its diagnosis, management, and current information, considering the recent literature status available in the different medical databases.

(c) The Author(s). 2021 Open Access This article is licensed under a Creative Commons Attribution 4.0 International License, which permits use, sharing, adaptation, distribution and reproduction in any medium or format, as long as you give appropriate credit to the original author(s) and the source, provide a link to the Creative Commons licence, and indicate if changes were made. The images or other third party material in this article are included in the article's Creative Commons licence, unless indicated otherwise in a credit line to the material. If material is not included in the article's Creative Commons licence and your intended use is not permitted by statutory regulation or exceeds the permitted use, you will need to obtain permission directly from the copyright holder. To view a copy of this licence, visit http://creativecommons.org/licenses/by/4.0/. 


\section{Main text}

\section{The persistent vegetative status}

The PVS is a neurological condition quite different from the other impaired consciousness states, which was first described by Jennet and Plum in 1972 as a status where the patient is "awake but unaware" of the surrounds [13, 14]. This term was used to describe the vegetative components of the nervous system [15]; it has been also known as apallic syndrome and, in the more recent studies, as unresponsive wakefulness syndrome [10, 16]. PVS is produced when a destructive injury takes place and affects the control awareness controller areas; this can be related to an anoxic-ischemic injury, a non-traumatic episode, a sTBI, and a complication or sequelae of a neurodegenerative disorder $[2,15,17,18]$. The autopsies of those reported cases have shown diffuse axonal injury, thalamic lesions, and axonal injuries in corpus callosum and rostral brainstem [15]. PVS is usually mediated by cortical, thalamic, and white matter injury rather than brain-stem injury [2]. The Royal College of Physicians guidelines classify it depending on the clinical examination and the time of onset: continuing VS (vegetative state), when the signs have been present for more than 4 weeks; chronic VS, an anoxic or metabolic brain injury for more than 3 months or if it is due to TBI after 1 year; and permanent VS, if an expert physician in PDoC diagnose it when there is no change in trajectory for 6 months (using the CRS-R) [16, 19]. On the other hand, American Academy of Neurology (AAN) classified VS as persistent VS when the patient is in clinical state for more than 1 month regardless if it is due to TBI or nonTBI and permanent VS applies 3 months after the nonTBI vegetative state and 12 months after TBI VS (with high probability of irreversibility) $[1,19]$.

\section{Current data and information regarding PVS}

The duration of the PVS depends on the nature of the brain damage, the duration of the unconscious period, and the estimated prognosis $[1,16]$. In post-traumatic vegetative states (where unconsciousness lasts for more than 28 days) 38, 67, and 78\% of patients regain consciousness at 3, 6, and 12 months, respectively. In nontraumatic vegetative states, 17 and $7.5 \%$ of patients regain consciousness at 6 and 24 months, respectively. Recovery of consciousness after 12 months in traumatic etiologies, and beyond 6 months in non-traumatic etiologies, is considered almost unlikely [20]. Erp et al. illustrate a problem that may arise from not knowing how to recognize manifestations of consciousness early, which means that on many occasions the patient is labeled as delayed recovery of consciousness, when in fact they show signs of consciousness within the expected periods of recovery. The authors refer this to the possibility of the lack of a standardized behavioral assessment in daily practice and the existence of inaccurate diagnostic terminology or the misinterpretation of conscious behavior [21].

\section{Clinical challenges}

The diagnosis of PVS is a challenge in the daily routine clinical care practice $[10,22]$; it is mainly based on the clinical history and the patient behavior observation to establish the correct PDoC diagnosis [12, 23, 24]. One of the main factors that complicates the diagnosis is the lack of a gold-standard with enough sensitivity and specificity to correctly stratify and categorize the PDoC patients [1]. After the brain injury, the level of consciousness is assessed based on the clinical examination and the patient ability to interact with the environment [25]. PVS patients present periods of wakefulness but are unaware of the situation or with an absence of environment or self-awareness signs [14, 26, 27]. They do not have voluntary behavior and there is no clinical evidence of interpretable contact of the patient with the surroundings (regardless if the patients seem awake with the eyes opened as mentioned before) [10, 13, 18]. PVS in other words is characterized by special movements (not related to neurotransmitter agents) and in some cases, altered circadian cycle that might persist for months [15]. During physical examination, the patient is briefly alert to stimulus but cannot respond to vigorous stimulation. The characteristics and diagnosis have some "special" features (Tables 1 and 2) [19].

\section{Diagnosis}

The diagnosis might be tricky specially if the physician is not well trained. It has been shown that in some cases, an important percentage of the patients with a PVS diagnosis, when evaluated by an experienced professional, are reclassified in other altered consciousness states [27]. The main causes of the misdiagnosis are related to the confusion in terminology, lack of experience of the

Table 1 Characteristics of a patient with a persistent vegetative status diagnosis (including atypical features) $[15,16]$

Primitive chewing movements and involuntary swallowing-gag reflex. Bulldog reflex.

Decorticate position (arm flexed, and legs extended).

Pathologic flexion/extension response (in some patients' absent motor response due to the early contractures and the predominant spasticity). Lack of purposeful response to external stimuli. Grasp reflexes.

Fumbling movements.

Often genitalia touching (specially in male patients).

Erections during REM (Rapid Eye Movement) Phase.

Spontaneous choreiform movements (of the head, limbs, and trunk).

Catatonic postures (e.g., salute position) that could be accompanied by dysautonomic features.

Opisthotonos.

Half sitting.

Non-purposeful limb movements and spontaneous gestures (e.g., smiling, crying, grunting, or screaming). 
Table 2 Diagnosis of vegetative state $[1,16]$

No evidence of awareness of themselves or their environment; they are incapable of interacting with others.

No evidence of sustained, reproducible, purposeful, or voluntary behavioral responses to visual, auditory, tactile, or noxious stimuli.

No evidence of language comprehension or expression. Intermittent wakefulness manifested by the presence of sleep-wake cycles. Sufficiently preserved hypothalamic and brainstem autonomic functions to survive if given medical and nursing care.

Bowel and bladder incontinence.

Variably preserved cranial nerve (pupillary, oculocephalic, corneal, vestibuleocular, and gag) and spinal reflexes.

physician, and the quite low-reported incidence of this condition [2]. The differentiation of PVS with other PDoC specially minimally conscious state (MCS) is challenging because the distinction is mainly based on behavioral observation [28]. Part of the challenge is mediated by the difficulty of the clinicians to identify appropriate responses of the patient to the different commands (sometimes it could be minimal or inconsistently present) [14, 18]. This is related to a $40 \%$ of misdiagnosed patients $[1,29]$. Schnakers et al. has shown that $41 \%$ of the patients with a PVS diagnosis were with a MCS instead when they were re-evaluated by an expert with a neurobehavioral scale, while some others had clear signs of consciousness in the standard examination [22]. The misdiagnosis (not only on these cases but in everything during medical practice) can lead to grave consequences, and especially on these patients, when there is an end-of-life decision-making [22, 30]. As a differential diagnosis, it is important to clarify other PDoC diagnostic criteria. MCS is characterized by the presence of reproducible and inconsistent directed behaviors as the response to commands or visual pursuit. This is a non-reflexive behavior and patients are unable to effectively communicate $[22,26]$. For comatose patients, there is a lack of arousal and unresponsiveness behavior, but when there is a sleep-wake cycle disturbance or eyes opening, the patient is evolving towards the VS [26], even though the absence of behavioral evidence for the command-following does not reflect a true absence of awareness or the ability to follow commands [14, 27, 31].

\section{Investigations}

In the search of a correct and definitive diagnosis, the type of assessment tool is very useful in an accurate diagnosis; over the years, specialized neurobehavioral rating scales have been proposed in the search of a reliable and valid diagnosis [22]. The Coma Recovery ScaleRevised (CRS-R) index is quite helpful in the practice; with this scale, the patient receives a simple instruction, when the movement is successful on 3 out of 4 trials, the patient is considered as "aware" (discarding the VS) $[10,14]$. The CRS-R contains an ordinal scale that goes from deepest possible coma (0 points) to awake and fully capable ( 23 points) category. This is very useful in the determination of the progress of the different DoC (from coma and the transition in every state) [10]. Till the date, multiple neuroimaging and neurological studies have been proposed to precisely reach the diagnosis, but according to some guidelines, there is still not enough evidence to consider their routine use [1]. This is also verified in the study of Landsness et al. They evidenced that in patients with PVS diagnosis, there is no pattern of normal electrophysiological sleep [26]. However, functional neuroimaging might be useful in the followcommand attempts [14]. Genetic studies have suggested altered tear proteomic profile, a potential tear protein marker which may be used for diagnosis and prognosis of the traumatic PVS [32].

\section{Management}

Giacino et al. showed some important gaps in knowledge of the PVS regarding the natural history, diagnosis, prognosis, management, and outcome [1]. Addressing the treatment of PVS requires a good knowledge of the injury, its repercussions, and the manifestations that the person presents, and even more so if it is secondary to trauma events. Interventions for treating these patients should include preventive and restorative strategies [33]. The therapeutic approach in these patients involves diagnostic confirmation, constant monitoring to verify potential changes, and systematically establishing preventive mechanisms for general, neurological, and orthopedic complications [34]. Although there is no consensus or universal guidelines for treatment, undoubtedly restoring sleep-wake cycles, nutritional balance, bowel and bladder regulation, and passive mobilization of large joints should be basic goals of clinical management $[33,34]$. These patients are at risk of immobility-related injuries, as thromboembolic disease, lung and urinary tract infections, pressure ulcers, muscles, and tendons compromise [34]. Proper nutrition often requires a percutaneous endoscopic gastrostomy (PEG) tube. A recent study demonstrates that PEG significantly improves the long-term survival of stroke patients in a PVS, and is also associated with better nutritional status and decreased lung infections [35].

There is very little evidence regarding specific treatment, and it has not yet been conclusively shown that any of them improves the patient's state of consciousness $[1,16]$. In studies where they mention a modest to complete recovery, they use therapy, and the effectiveness of this has not been proven. Various medications have been proposed as wakeful stimulants including dopaminergics, classic stimulants, and tricyclic antidepressants [36-38]. The literature reports that patients with PVS and spasticity after traumatic or spontaneous brain damage improved their state of consciousness after 
intrathecal administration of Baclofen [39-42]. Although they are all case reports, there is no clear argument to support the indication of Baclofen for improving the level of consciousness. It is recommended that studies with a control group be carried out to clarify the effect of Baclofen on the level of consciousness in patients with brain damage. In a study of 175 patients made by $\mathrm{Du}$ et al., after administration of Zolpidem, they observed that it restored brain function in patients in vegetative state after brain injury, especially in the group of patients whose injuries did not affect the brain stem [43]. In a case report of a patient in PVS secondary to subarachnoid hemorrhage, after administration of Amantadine, improvement seen after 16 days of treatment was evidenced. Amantadine was initially used for influenza, but has been shown to indirectly increase central dopamine $[39,44]$. In a prospective study, Magrassi et al. observed that bilateral thalamic stimulation may improve the clinical status of patients affected by a disorder of consciousness (including PVS) despite the fact that this stimulation did not induce persistent and clinically evident conscious behavior in patients [45]. Vanhoecke and Hariz performed a systematic review of the literature on deep brain stimulation in patients with DoC and demonstrated that this technique is far from evident as a possible future therapeutic route for patients with $\mathrm{PDoC}$ [46]. The proposed treatments for DoC have not reached the level of "evidence-based treatments", so more studies with solid methodology and with a larger number of patients are needed.

\section{Prognosis}

According to the AAN Guideline, when assessing the natural history outcome of patients with PVS due to a TBI episode, there is insufficient evidence to conclude the frequency, the recovery of consciousness rate, or any other outcomes [1]. Regarding non-TBI PVS, the guideline says that it is possible a 3-month survival in an $80 \%$ of the cases, $17 \%$ will recover the consciousness at 6 months, and $60 \%$ of the cases will survive to even 8 months [1]. The prognosis or survival of the PDoC patients (regardless if they present PVS, MCS, or any other) is related to the structural cause (brain injury, stroke, anoxia-ischemia, meningitis, etc.), the age of the patient, and the organ involvement [6]; however, prognosis is usually affected by three major factors: the time spent in the PVS, the patient age, and the injury etiology [2]. The fluctuation of the outcome prognosis (good or bad) may be frequent during the clinical evolution, even though the outcome is often determined at the beginning of the case or brain injury severity [6]. In one study, the role of time prognosis when comparing 603 published cases of adults with PVS, the chance of recovering independence at 1 year decreased over time from the first month, after 3 months and 6 months (18\%, 12\%, and $3 \%$ respectively), as well, the consciousness recovery rate decreased in a $42 \%, 27 \%$, and $12 \%$ and the chances to stay in the VS at 1 year were $19 \%, 35 \%$, and $57 \%$ respectively (in both situations) in the same amount of time [2]. Some literature indicates that the approximate recovery time of consciousness for the patients in PVS by a TBI might be after 12 months and within 3 to 6 months for those with PVS by non-traumatic injuries [29]. It is important to bear in mind that patients could survive decades regardless the prognostic and recovery boundaries $[7,29]$. According to some evidence, 10 to $24 \%$ of PVS patients might regain consciousness after the event, but they could present marked functional impairment, and for younger patients, a better recovering rate and prognosis has been evidenced [2, 10]. For Monti et al., TBI PVS is associated with better prognosis and outcomes at 1 year compared to non-TBI PVS when considering recovery of independence $(24 \%$ vs $4 \%$ respectively), and recovery of consciousness of $52 \%$ vs $13 \%$ of the cases [2]. Nevertheless, when permanent VS is diagnosed, the recovery chances are "extremely low" and is associated with severe disability, although on occasions, the literature has shown late PVS recoveries [2].

\section{Medical practice and bioethical challenges}

There is a group of patients who are misdiagnosed with PVS, having manifestations of consciousness; although it is a situation according to the very rare literature, the percentage is around (according to a recent systematic review) the $34 \%$ of patients [47]. Therefore, a comprehensive neurological examination and daily measurement of consciousness with standardized scales is recommended. On the other hand, we understand that the PVS raises ethical debates, and it is never easy to make decisions about what is the best intervention for them, so it is very important to understand and know how most people see this type of patient. Because of some "miraculous recoveries" and the misdiagnosis rate, the reversal and confident diagnosis of the PVS has been doubted over the years affecting also the patients family perspective $[6,12]$. In a perception study carried out by Gray et al. in 2011, they show us that people see PVS as a particularly "more dead than dead" state; in this study, they conducted three experiments: the first found that patients with PVS were perceived to have less mental capacity than the dead; in turn, in the second experiment, they explained that this perception was possibly a consequence of post-life beliefs; and in the third experiment, PVS was found to be perceived as "worse" than death [48]. This study shows us that most people perceive that it is better to die than to live in a PVS, so it is very important for decision-making to recognize that almost nobody wants to maintain a life indefinitely in a 
VS. Legal challenges cannot be ignored especially with younger patients' population. In this group of patients, the common elements leading to severe neurological injury and ultimately PVS include trauma, drug use, and overdoses. Multiple cases over the last few decades have shown that elements of early care and progression have major bearing on what transpires once PVS is established. Paucity of data connecting early phase with later medico-legal course is not clear and future studies are needed to better discern this realm of care in these complex patients.

\section{Conclusions}

Nowadays, regardless of recent guidelines and manuscripts that can be found in the different databases, there is still a lot that we do not know about the DoC especially PVS. The diagnosis without an adequate clinical scale is very challenging [26]. The initial assessment and identification of etiology could present an improvement for the patient's prognosis. Further, according to some literature, when patients go rapidly in the early stages through the different PDoC, they likely recover with consciousness and better functional independence outcomes [16]. Still, there is limited evidence regarding the way to achieve an optimal diagnosis that allows the physician to expect a natural history of the PVS and improve the outcomes with the appropriate treatment [1]. For what is worth, it, in the daily routine, is important to keep treating the patient in the avoidance of immobilityrelated injuries and intensive care unit long-stance. Connecting early care with extend course needs formal studies.

\footnotetext{
Abbreviations

AAN: American Academy of Neurology; CRS-R: Coma Recovery Scale-Revised; MCS: Minimally conscious state; PDoC: Prolonged disorder of consciousness; PEG: Percutaneous endoscopic gastrostomy; PVS: Persistent vegetative state; REM: Rapid eye movement; sTBI: Severe traumatic brain injury; TBI: Traumatic brain injury; VS: Vegetative state
}

\section{Acknowledgements}

None.

\section{Authors' contributions}

All the authors meet the authorship requirements; they all made substantial contributions to conception of the manuscript regarding the contribution to conception and design, acquisition of data and the correspondent interpretation, drafting the article, and making the critically revision of the intellectual content. All the authors have read and approved the manuscript final version. GAQ-O, YAD-E, JT, LRM-S, and AA: conception, design of the work, acquisition, analysis, interpretation of data, drafted the work, and substantively revised it. GAQ-O, YAD-E, JT, LRM-S, and AA: creation of new software used in the work. Not applicable. All the authors have approved the submitted version (and any substantially modified version that involves the authors' contributions to the study). All the authors have agreed both to be personally accountable for the authors' own contributions and to ensure that questions related to the accuracy or integrity of any part of the work, even ones in which the authors were not personally involved, are appropriately investigated, resolved, and the resolution documented in the literature.
Funding

Not applicable. There was no funding.

Availability of data and materials

Not applicable.

\section{Declarations}

\section{Ethics approval and consent to participate}

Not applicable. The present manuscript has not been submitted to other journal for simultaneous consideration. The manuscript has not been published previously and is not split up in other parts, no data have been manipulated or fabricated, and no information is presented as if were from the authors.

\section{Consent for publication}

Not applicable.

\section{Competing interests}

The authors declare that they have no competing interests.

\section{Author details}

${ }^{1}$ Faculty of Medicine, Universidad El Bosque, Bogotá, Colombia. ${ }^{2}$ Cartagena Neurotrauma Research Group research line, Faculty of Medicine, University of Cartagena, Cartagena de Indias, Colombia. ${ }^{3}$ Center for Biomedical Research (CIB), Cartagena Neurotrauma Research Group research line, Faculty of Medicine, University of Cartagena, Cartagena de Indias, Colombia. ${ }^{4}$ Department of Neurology and Critical Care Medicine, Regions Hospital, Saint Paul, MN, USA. ${ }^{5}$ RED LATINO, Organización Latinoamericana de Trauma y cuidado Neurointensivo, Bogota, Colombia. ${ }^{6}$ Consejo Latinoamericano de Neurointensivismo- CLaNi, Cartagena, Colombia. ${ }^{7}$ Department of Neurosurgery, All India Institute of Medical Sciences, Saket Nagar, Bhopal, Madhya Pradesh, India.

Received: 9 January 2021 Accepted: 15 April 2021

Published online: 01 July 2021

\section{References}

1. Giacino JT, Katz DI, Schiff ND, Whyte J, Ashman EJ, Ashwal S, Barbano R, Hammond FM, Laureys S, Ling GSF, Nakase-Richardson R, Seel RT, Yablon S, Getchius TSD, Gronseth GS, Armstrong MJ Comprehensive systematic review update summary: Disorders of consciousness: Report of the Guideline Development, Dissemination, and Implementation Subcommittee of the American Academy of Neurology; The American Congress of Rehabilitation Medicine; And the. Neurology 2018;91(10):461-470, doi: https://doi.org/10.1212/WNL.0000000000005928.

2. Monti MM, Laureys S, Owen AM. The vegetative state. BMJ. 2010;341(7767): 292-6.

3. Dunne J, Quiñones-Ossa GA, Still EG, et al. The epidemiology of traumatic brain injury due to traffic accidents in Latin America: A Narrative Review. J Neurosci Rural Pract. 2020;11(02):287-90.

4. Carney N, Totten AM, O'Reilly C, et al. Guidelines for the management of severe traumatic brain injury, Fourth Edition. Neurosurgery. 2016;80(1):1.

5. Dewan MC, Rattani A, Gupta S, et al. Estimating the global incidence of traumatic brain injury. J Neurosurg. 2018;1 (aop):1-18.

6. Wijdicks EFM. Minimally conscious state vs persistent vegetative state: The case of Terry (Wallis) vs the case of Terri (Schiavo). Mayo Clin Proc. 2006; 81(9):1155-8. https://doi.org/10.4065/81.9.1155.

7. van Erp WS, Lavrijsen JCM, Vos PE, Bor H, Laureys S, Koopmans RTCM. The vegetative state: Prevalence, misdiagnosis, and treatment limitations. J Am Med Dir Assoc. 2015;16(1):85.e9-85.e14.

8. Beaumont JG, Kenealy PM. Incidence and prevalence of the vegetative and minimally conscious states. Neuropsychol Rehabil. 2005;15(3-4):184-9. https://doi.org/10.1080/09602010443000489

9. Tang Q, Lei J, Gao G, Feng J, Mao Q, Jiang J. Prevalence of persistent vegetative state in patients with severe traumatic brain injury and its trend during the past four decades: a meta-analysis. NeuroRehabilitation. 2017; 40(1):23-31. https://doi.org/10.3233/NRE-161387.

10. Bender A, Jox RJ, Grill E, Straube A, Lulé D. Persistent vegetative state and minimally conscious state: a systematic review and meta-analysis of 
diagnostic procedures. Dtsch Arztebl Int. 2015;112(14):235-42. https://doi. org/10.3238/arztebl.2015.0235.

11. Kuehlmeyer K, Racine E, Palmour N, Hoster E, Borasio GD, Jox RJ. Diagnostic and ethical challenges in disorders of consciousness and locked-in syndrome: A survey of German neurologists. J. Neurol. 2012;259(10):207689. https://doi.org/10.1007/s00415-012-6459-9.

12. Kuehlmeyer K, Palmour N, Riopelle RJ, Bernat JL, Jox RJ, Racine E. Physicians' attitudes toward medical and ethical challenges for patients in the vegetative state: Comparing Canadian and German perspectives in a vignette survey. BMC Neurol 2014;14(1). https://doi.org/10.1186/1471-23 77-14-119.

13. Jennett B, Plum F. Persistent vegetative state after brain damage. A syndrome in search of a name. Lancet 1972;299(7753):734-7, 737, doi: https://doi.org/10.1016/s0140-6736(72)90242-5.

14. Cruse D, Chennu S, Fernández-Espejo D, Payne WL, Young GB, Owen AM. Detecting awareness in the vegetative state: electroencephalographic evidence for attempted movements to command. Plos One. 2012;7(11): e49933. https://doi.org/10.1371/journal.pone.0049933.

15. Wijdicks EFM, Cranford RE. Clinical diagnosis of prolonged states of impaired consciousness in adults. Mayo Clin Proc. 2005;80(8):1037-46. https://doi.org/10.4065/80.8.1037.

16. Turner-Stokes, Lynne; Wade, Derick; Playford, Diane; Kitzinger, Jenny ;Allanson, Judith ; Pundole A et al. Prolonged disorders of consciousness following sudden onset brain injury: national clinical guidelines. UK: Royal College of Physicians; 2020

17. Laureys S, Owen AM, Schiff ND. Brain function in coma, vegetative state, and related disorders. Lancet Neurol. 2004;3(9):537-46. https://doi.org/10.1 016/S1474-4422(04)00852-X.

18. Crone JS, Ladurner G, Höller Y, Golaszewski S, Trinka E, Kronbichler M. Deactivation of the default mode network as a marker of impaired consciousness: an fMRI study. Plos One. 2011;6(10):e26373. https://doi.org/1 0.1371/journal.pone.0026373.

19. Boone MD, Nozari A, Fehnel CR. Coma. In: Parsons MD PE, Wiener-Kronish MD JP, Stapleton MD, PHD RD, Berra MD L, editors. Critical Care Secrets. 2019. p. 393-402.

20. Multi-Society Task Force. Medical aspects of the persistent vegetative state. N Engl J Med. 1994;330(22):1572-9.

21. van Erp WS, Aben AML, Lavrijsen JCM, Vos PE, Laureys S, Koopmans RTCM Unexpected emergence from the vegetative state: delayed discovery rather than late recovery of consciousness. J Neurol. 2019;266:3144-9. https://doi. org/10.1007/s00415-019-09542-3.

22. Schnakers C, Vanhaudenhuyse A, Giacino J, Ventura M, Boly M, Majerus S, et al. Diagnostic accuracy of the vegetative and minimally conscious state: clinical consensus versus standardized neurobehavioral assessment. BMC Neurol. 2009;9(1):35. https://doi.org/10.1186/1471-2377-9-35.

23. Bernat JL. Chronic disorders of consciousness. Lancet. 2006:367(9517):118192. https://doi.org/10.1016/S0140-6736(06)68508-5.

24. Ragazzoni A, Pirulli C, Veniero D, et al. Vegetative versus minimally conscious states: a study using TMS-EEG, sensory and event-related potentials. Plos One 2013;8(2). https://doi.org/10.1371/journal.pone.0057069.

25. Rosanova M, Gosseries O, Casarotto S, Boly M, Casali AG, Bruno MA, et al. Recovery of cortical effective connectivity and recovery of consciousness in vegetative patients. Brain. 2012;135(4):1308-20. https://doi.org/10.1093/bra in/awr340.

26. Landsness E, Bruno M-AA, Noirhomme Q, Riedner B, Gosseries O, Schnakers $C$, et al. Electrophysiological correlates of behavioural changes in vigilance in vegetative state and minimally conscious state. Brain. 2011;134(8):222232. https://doi.org/10.1093/brain/awr152.

27. Cruse D, Chennu S, Chatelle C, Bekinschtein TA, Fernández-Espejo D, Pickard $J \mathrm{D}$, et al. Bedside detection of awareness in the vegetative state: A cohort study. Lancet. 2011;378(9809):2088-94. https://doi.org/10.1016/S0140-673 6(11)61224-5.

28. Berger JR. Stupor and Coma. In: Daroff MD RB, Jankovic MD J, Mazziotta MD, PhD JC, Pomeroy MD, PhD SL, editors. Bradley's Neurology in Clinical Practice. 2016. p. 34-50.e1.

29. Span-Sluyter CAMFH, Lavrijsen JCM, Van Leeuwen E, Koopmans RTCM Moral dilemmas and conflicts concerning patients in a vegetative state/ unresponsive wakefulness syndrome: shared or non-shared decision making? A qualitative study of the professional perspective in two moral case deliberations. BMC Med Ethics 2018;19(1). https://doi.org/10.1186/s1291 0-018-0247-8
30. Andrews K. Medical decision making in the vegetative state: withdrawal of nutrition and hydration. NeuroRehabilitation. 2004;19(4):299-304.

31. Cruse D, Chennu S, Chatelle C, Fernandez-Espejo D, Bekinschtein TA, Pickard $\mathrm{JD}$, et al. Relationship between etiology and covert cognition in the minimally conscious state. Neurology. 2012;78(11):816-22. https://doi.org/1 0.1212/WNL.0b013e318249f764.

32. Tang Q, Zhang C, Wu X, Duan W, Weng W, Feng J, et al. Comprehensive proteomic profiling of patients' tears identifies potential biomarkers for the traumatic vegetative state. Neurosci Bull. 2018;34(4):626-38. https://doi.org/1 0.1007/s12264-018-0259-x.

33. Hirschberg R, Giacino JT. The vegetative and minimally conscious states: diagnosis, prognosis and treatment. Neurol. Clin. 2011;29(4):773-86. https:// doi.org/10.1016/j.ncl.2011.07.009.

34. Giacino JT, Trott $C$. Rehabilitative management of patients with disorders of consciousness. J Head Trauma Rehabil. 2004;19(3):254-65. https://doi. org/10.1097/00001199-200405000-00006.

35. Wu K, Chen Y, Yan C, Huang Z, Wang D, Gui P, et al. Effects of percutaneous endoscopic gastrostomy on survival of patients in a persistent vegetative state after stroke. J Clin Nurs. 2017;26(19-20):3232-8. https://doi.org/1 $0.1111 /$ jocn.13672.

36. Georgiopoulos M, Katsakiori P, Kefalopoulou Z, Ellul J, Chroni E, Constantoyannis $C$. Vegetative state and minimally conscious state: a review of the therapeutic interventions. Stereotact. Funct. Neurosurg. 2010. https:// doi.org/10.1159/000314354.

37. Matsuda W, Komatsu Y, Yanaka K, Matsumura A. Levodopa treatment for patients in persistent vegetative or minimally conscious states. Neuropsychol Rehabil. 2005;15(3-4):414-27. https://doi.org/10.1080/0960201 0443000588.

38. Clauss R, Nel W. Drug induced arousal from the permanent vegetative state. NeuroRehabilitation. 2006;21 (1):23-8. https://doi.org/10.3233/NRE-2006-21104.

39. Margetis K, Korfias SI, Gatzonis S, Boutos N, Stranjalis G, Boviatsis E, et al. Intrathecal baclofen associated with improvement of consciousness disorders in spasticity patients. Neuromodulation Technol Neural Interface. 2014;17(7):699-704. https://doi.org/10.1111/ner.12147.

40. Asahi T, Kashiwazaki D, Koh M, Matsumura N, Kuroda S. Complete remission of consciousness disturbances and spasticity due to a severe subarachnoid hemorrhage after intrathecal baclofen therapy: A case report. Neurol Surg. 2015;43(3):253-7. https://doi.org/10.11477/mf.1436202997.

41. Sacher $Y$, Cismariu-Potash K, Zion Z. Improved response after intrathecal administration of baclofen in a patient with impaired consciousness - a case study. Ann Phys Rehabil Med. 2018;61:e366. https://doi.org/10.1016/j. rehab.2018.05.849.

42. Espigares Correa G, Benito-Penalva J. Intrathecal baclofen therapy in brain injury and recovery of persistent vegetative state. Apropos of a case. Rehabilitacion. 2020;54(2):137-41. https://doi.org/10.1016/j.rh.2019.12.004.

43. Du B, Shan A, Zhong X, Zhang Y, Chen D, Cai K. Zolpidem arouses patients in vegetative state after brain injury: quantitative evaluation and indications. Am J Med Sci. 2014:347(3):178-82. https://doi.org/10.1097/MAJ.0b013e3182 $87 \mathrm{c} 79 \mathrm{c}$.

44. Lehnerer SM, Scheibe F, Buchert R, Kliesch S, Meisel A. Awakening with amantadine from a persistent vegetative state after subarachnoid haemorrhage. BMJ Case Rep. 2017;2017:bcr-2017-220305.

45. Magrassi L, Maggioni G, Pistarini C, di Perri C, Bastianello S, Zippo AG, et al. Results of a prospective study (CATS) on the effects of thalamic stimulation in minimally conscious and vegetative state patients. J Neurosurg. 2016; 125(4):972-81. https://doi.org/10.3171/2015.7.JNS15700.

46. Vanhoecke J, Hariz M. Deep brain stimulation for disorders of consciousness: systematic review of cases and ethics. Brain Stimul. 2017;10(6):1013-23. https://doi.org/10.1016/j.brs.2017.08.006.

47. Wade DT. How often is the diagnosis of the permanent vegetative state incorrect? A review of the evidence. Eur. J. Neurol. 2018;25(4):619-25. https://doi.org/10.1111/ene.13572. Epub 2018 Feb 16.

48. Gray K, Anne Knickman T, Wegner DM. More dead than dead: Perceptions of persons in the persistent vegetative state. Cognition. 2011;121(2):275-80. https://doi.org/10.1016/j.cognition.2011.06.014

\section{Publisher's Note}

Springer Nature remains neutral with regard to jurisdictional claims in published maps and institutional affiliations. 